\title{
Correction to: Acute and long-term outcomes of epicardial left atrial appendage ligation with the second-generation LARIAT device: a high- volume electrophysiology center experience
}

\author{
Thomas Fink ${ }^{1}$ (1) - Michael Schlüter ${ }^{1} \cdot$ Roland Richard Tilz $^{1,2} \cdot$ Christian-Hendrik Heeger $^{1}$. Christine Lemes ${ }^{1}$. \\ Tilmann Maurer ${ }^{1}$. Bruno Reissmann ${ }^{1} \cdot$ Laura Rottner $^{1} \cdot$ Francesco Santoro $^{1} \cdot$ Shibu Mathew $^{1} \cdot$ Andreas Rillig $^{1}$. \\ Feifan Ouyang ${ }^{1} \cdot$ Karl-Heinz Kuck $^{1} \cdot$ Andreas Metzner $^{1}$
}

Published online: 2 July 2018

(c) Springer-Verlag GmbH Germany, part of Springer Nature 2018

\section{Correction to: Clinical Research in Cardiology https://doi.org/10.1007/s00392-018-1288-1}

Unfortunately, an error occurred in the conclusion section of this article. The corrected conclusion text is given below.

\section{Conclusion}

The current study found a considerably high procedural success rate with regard to acute LAA ligation, an incidence of major periprocedural complications of $6 \%$, and a significant rate of incomplete LAA ligation during follow-up, requiring continuation of oral anticoagulation in affected patients. No intracardiac thrombus formation and only a single thromboembolic event occurred during follow-up. We, therefore, conclude that epicardial LAA ligation might be a feasible option for LAA exclusion, but with respect to its invasiveness it should only be performed in selected patients and in centers with experience in dry epicardial puncture and back up cardiac surgery.
The original article can be found online at https://doi.org/10.1007/ s00392-018-1288-1.

Andreas Metzner

a.metzner@asklepios.com

1 Department of Cardiology, Asklepios Klinik St. Georg,

Lohmühlenstr. 5, 20099 Hamburg, Germany

2 Present Address: University Heart Center, Lübeck, Germany 